\title{
CARACTERIZAÇÃo FÍSICA, FÍSICO-QUIIMICA, ENZIMÁTICA E DE PAREDE CELULAR EM DIFERENTES ESTÁDIOS DE DESENVOLVIMENTO DA FRUTA DE FIGUEIRA ${ }^{1}$
}

\author{
Carlos Antonio A. GONÇALVES ${ }^{2, *}$, Luiz Carlos de O. LIMA³, \\ Paulo Sérgio N. LOPES ${ }^{4}$, Mônica Elisabeth T. PRADO ${ }^{5}$
}

\begin{abstract}
RESUMO
Com o objetivo de avaliar a caracterização física, físico-química, enzimática e de parede celular, durante os diferentes estádios de desenvolvimento dos frutos da figueira sob irrigação, no norte de Minas Gerais, o presente trabalho foi desenvolvido durante o ciclo de produção 2001/2002, na Unidade de Produção Frutícola da Escola Agrotécnica Federal de Salinas (Eafsal), município de Salinas. Utilizaram-se, neste experimento, plantas com dois anos e meio de idade após o transplantio e com 12 ramos primários (pernadas), bem desenvolvidos e espaçamento de 2,5x1,5 m. O delineamento aplicado foi inteiramente casualizado, com duas repetições e um total de 40 plantas marcadas. Os dados coletados foram referentes ao ciclo de produção 2001/2002, para as plantas podadas em junho. Avaliou-se, durante os diferentes estádios de desenvolvimento dos frutos da figueira, a atividade enzimática, composição química, avaliações físicas, açúcares neutros e compostos de parede celular. À medida que a atividade de polifenoloxidase e peroxidase foi diminuindo, a atividade da poligalacturonase aumentou, no decorrer do desenvolvimento dos frutos. Os frutos atingiram ponto de colheita para a indústria e consumo in natura aos 30 e 75 dias da diferenciação das gemas em sicônio, respectivamente. Ocorreu um aumento significativo nos teores de sólidos solúveis totais, açúcares solúveis totais e redutores durante o desenvolvimento do fruto. O valor de pH e o conteúdo de acidez total titulável variaram muito pouco durante o desenvolvimento do fruto. O diâmetro médio dos frutos foi sempre inferior ao comprimento médio, atingindo 51,99 $\mathrm{mm}$ e 59,18 mm, respectivamente, aos 75 dias. Quanto ao peso médio, os frutos atingiram $53,23 \mathrm{~g}$ aos 75 dias. Os açúcares neutros predominantes foram a galactose, a arabinose e a xilose, enquanto fucose, manose, glucose e ramnose apresentaram-se em menor quantidade na parede celular durante os diferentes estádios de desenvolvimento dos frutos. Com a maturação dos frutos, houve redução dos principais componentes dos polissacarídeos pécticos (galactose, arabinose e ramnose), enquanto os componentes da fração hemicelulósica (xilose, glucose e manose) tenderam a aumentar. A solubilização da celulose e queda nos teores de hemicelulose se deu a partir dos 60 dias, quando o fruto, já na maturidade fisiológica, inicia o processo de amaciamento, em função da solubilização de pectinas, pela maior atividade das enzimas pectinametilesterase e poligalacturonase.

Palavras-chave: Ficus carica L., caracterização, desenvolvimento, fruto.
\end{abstract}

\section{SUMMARY}

PHYSICAL, CHEMICO-PHYSICAL, ENZYMATIC AND CELL WALL CHARAZTERIZATION DURING THE DIFFERENT DEVELOPMENT STAGES OF THE FIG TREE FRUITS. With the objective of evaluating the physical, physical-chemical, enzymic and cell wall characterization during the different developmental stages of the fig tree fruits under irrigation in Northern Minas Gerais, the present work was developed during the 2001/2002 cropping cycle in the Unidade de Produção Frutícola da Escola Agrotécnica Federal de Salinas (Fruit Growing Unit of the Federal Agrotechnical School of Salinas (Eafsal), town of Salinas. Plants of two years and a half after transplanting and with twelve well developed primary branches (pernadas = the first strong branches of a tree) and $2.5 \times 1.5 \mathrm{~m}$ spacing were utilized in this experiment. The design applied was completely randomized with two replicates and a total of 40 marked plants. The data collected were concerning 2001/2002 cropping cycle for the June-pruned plants. Evaluated during the different developmental stages of fig tree fruits activity of the enzimes, chemical composition, physical evaluate, neutral sugars and cell wall components. As polyphenoloxidase and peroxidase activity was decreasing, polygalacturonase activity increased throughout the development of the fruits. The fruits reached harvest point for industry and in natura consumption at 30 and 75 days from the differentiation of the buds in syconium, respectively. A significant increase took place in the contents of total soluble solids, total soluble and reducing sugars during the development of the fruit. Both pH and TTA ranged very little during fruit development. The average diameter of the fruits was always inferior to the average length, reaching $51.99 \mathrm{~mm}$ and $59.18 \mathrm{~mm}$, respectively at 75 days. The average weight of $53.23 \mathrm{~g}$ was reached at 75 days. Predominating neutral sugars were galactose, arabinose and xylose whereas fucose, mannose and glucose and rhamnose were those present in smaller amount in the cell wall during the different developmental stages of the fruits. With the maturation of the fruits, there was a reduction of the chief components of pectic polysaccharides (galactose, arabinose and rhamnose), whilst the components of the hemicellulose fraction (xylose, glucose and mannose) tended to increase. Cellulose solubilization and fall in the contents of hemicellulose took place from 60 days when the fruit already in the physiological maturity, starts softening process, as related with pectin solubilization by the higher activity of the pectinnemethylesterase and polygalacturonase enzymes.

Keywords: Ficus carica L., characterization, development, fruit.

\footnotetext{
${ }^{1}$ Recebido para publicação em 27/6/2005. Aceito para publicação em 23/1/2006 (001556)

${ }^{2}$ Professor do Centro Federal de Educação Tecnológica (Cetef) de Uberaba (MG)

Avenida Edilson Lamartine Mendes, 3.000 - Parque das Américas CEP 38045-000 - Uberaba (MG)

E-mail:caeafsal@hotmail.com

${ }^{3}$ Professor do Departamento de Ciência dos Alimentos. Universidade Federal de Lavras (Ufla), Lavras (MG)

${ }^{4}$ Professor do Departamento de Agricultura. Universidade Federal de Minas Gerais (UFMG), Montes Claros (MG)

${ }^{5}$ Pesquisadora do Departamento de Ciência dos Alimentos. Ufla, Lavras (MG) *A quem a correspondência deve ser enviada
}

\section{1 - INTRODUÇÃO}

A figueira (Ficus carica L.) pertence à família das moráceas e é originária da Ásia Menor e Síria, de onde se dispersou posteriormente pelos países da Bacia Mediterrânea [31].

Atualmente, tem sido introduzido no norte de Minas Gerais o cultivo da figueira. Nessa região, além da possibilidade de se obter safras com produtividade superior às das áreas tradicionais, é possível obter safras extemporâneas, como ocorre em outras localidades de condições climáticas semelhantes. Entretanto, tambem é importante a qualidade dos frutos produzidos no norte de Minas Gerais, pois cada 
vez mais o mercado de frutos para a indústria e consumo in natura tem considerado bastante os padrões de qualidade, no momento da aquisição da safra.

Uma série de mudanças físicas, físico-químicas, químicas e bioquímicas acontece durante o desenvolvimento dos frutos. O padrão de crescimento dos frutos pode ser estudado pelas modificações físicas. Na formação de características relacionadas ao sabor (figos maduros) e tecnologia de processamento da fruta industrializada (figos verdes), são importantes as alterações na composição dos ácidos orgânicos, carboidratos e pH. O amaciamento do fruto é atribuído à perda de firmeza dos tecidos e está associado a mudanças na composição da parede celular, em decorrência de alterações na estrutura e composição dos carboidratos, como pectinas, hemicelulose e celulose. Diversas enzimas catalizam reações metabólicas na parede celular de frutos.

O conhecimento da estrutura da parede celular é importante para a tecnologia pós-colheita e para a definição de procedimentos na transformação industrial de produtos vegetais. A definição de uma estratégia para promover um amadurecimento uniforme do fruto para consumo in natura depende do conhecimento das reações bioquímicas que ocorrem nesses componentes da célula. Na fabricação de doces em barra (textura de corte), em calda e licores, o conhecimento da constituição da parede celular da fruta verde da figueira torna-se fundamental para definir etapas na indústria.

O estudo mais detalhado do padrão de desenvolvimento do fruto e das principais mudanças decorrentes do amadurecimento, que levam à senescência, será de extrema importância na adoção de novas tecnologias para a melhoria dos processos de industrialização do figo verde e conservação pós-colheita do figo in natura.

Portanto, o presente trabalho teve por objetivo avaliar a caracterização física, físico-química, química e bioquímica, com ênfase nas modificações da parede celular, durante os diferentes estádios de desenvolvimento do fruto da figueira no norte de Minas Gerais.

\section{2 - MATERIAL E MÉTODOS}

\section{1 - Caracterização de cultivo da matéria-prima}

Os frutos de figueira variedade roxo de Valinhos foram colhidos de plantas localizadas na Unidade Demonstrativa de Produção Frutícola da Escola Agrotécnica Federal de Salinas, situada no município de Salinas, ao norte de Minas Gerais, durante o ciclo agrícola 2001/2002. O referido local situa-se a $16^{\circ} 10^{\prime} 10^{\prime \prime}$ de latitude sul e $42^{\circ} 17^{\prime} 33^{\prime \prime}$ de longitude $\mathrm{W}$ e a $427 \mathrm{~m}$ de altitude.

Seu clima apresenta temperatura média anual de $25^{\circ} \mathrm{C}$, umidade relativa média de $65 \%$, precipitação pluviométrica total anual variando de 700 a $1.200 \mathrm{~mm}$, concentrando o período chuvoso no período de outubro a abril, e insolação média anual em torno de $1.980 \mathrm{~h}$.
O solo é do tipo latossolo aermelho amarelo com textura areno argilosa, irrigado por meio de microaspersão. Os tratos culturais regulares de capina, roçada, tratamentos fitossanitários, podas de formação e condução e adubações seguiram as recomendações de ABRAHÃO et al.[1] .

\section{2 - Instalação do experimento e preparo das amostras}

Os frutos foram colhidos de 40 plantas de figueira, implantadas em espaçamento de $2 \mathrm{~m} \times 1,5 \mathrm{~m}$, com três anos de idade (plantas), conduzidas no sistema de condução sem desponte e com 12 ramos [1]. Antes da colheita, efetuou-se a marcação dos frutos individualmente com fitas coloridas, em que cada cor representou um dos cinco estádios de desenvolvimento dos frutos. A marcação dos frutos ocorreu em todos os ramos produtivos nas posições superior, inferior, externa e interna da planta. Após a colheita de $500 \mathrm{~g}$ de frutos por parcela, os mesmos foram lavados em água pura+0,5\% de hipoclorito de sódio, para se evitar a queima dos frutos pela ação da ficina (enzima presente no látex exsudado após a retirada do fruto).

Na manhã seguinte à colheita, os frutos foram acondicionados em jornal umedecido, envolvidos em sacos de polietileno, colocados em caixa de isopor e enviados, via terrestre, para Lavras (MG), distante $880 \mathrm{~km}$ de Salinas. Este período de transporte levou aproximadamente $15 \mathrm{~h}$.

Em Lavras (MG), os frutos foram transferidos para o Laboratório de Bioquímica de Frutos pertencente ao Departamento de Ciência dos Alimentos da Universidade Federal de Lavras (Ufla). Cada tratamento, representado pelo estádio de desenvolvimento dos frutos, foi composto por 500 g de frutos para a execução das análises. Uma parte dos frutos foi utilizada para as determinações físicas, e o restante, congelado em nitrogênio líquido, acondicionados a vácuo em sacos de polietileno (tipo vac-freezer) e estocados em freezer a $-86^{\circ} \mathrm{C}$ até a execução das análises químicas, enzimáticas e de parede celular. Para as análises químicas e enzimáticas, utilizou-se $15 \mathrm{~g}$ de fruto por parcela, tendo as mesmas sido feitas em duplicata.

\section{3 - Determinação da atividade de enzimas hidrolíticas de parede celular}

A atividade da pectinesterase foi determinada por titulação dos grupos carboxílicos liberados pela desesterificação da pectina devido à ação da enzima, pectinametilesterase (PME), de acordo com o método descrito por JEN \& ROBINSON [24]. Utilizou-se como substrato uma solução de pectina cítrica a $1 \%$ em $\mathrm{NaCl}$ 0,2N, pH 7,0, à temperatura ambiente. A taxa de desmetilação da pectina, adicionada ao extrato enzimático, foi medida pela titulação da mistura de reação com $\mathrm{NaOH} 0,01 \mathrm{~N}$, mantendo-se o pH 7,0 por $10 \mathrm{~min}$. A unidade de atividade enzimática (UAE) foi definida como sendo a capacidade da enzima de catalizar a desmetilação de pectina correspondente a 1 nanomol de $\mathrm{NaOH}$ nas condições do ensaio. Os resultados foram expressos em unidades de atividade enzimática por minuto por grama de peso fresco (U.min ${ }^{1} \cdot g^{-1}$ ). 
A atividade da poligalacturonase (PG) foi determinada pela medida dos grupos redutores liberados do ácido poligalacturônico, segundo metodologia de PRESSEY \& AVANTS [36]. A atividade foi determinada incubando-se o extrato enzimático com solução de ácido poligalacturônico a $0,25 \%$, em tampão acetato de sódio 37,5 $\mathrm{mM}, \mathrm{pH} 5$, a $30^{\circ} \mathrm{C}$, por $3 \mathrm{~h}$. A reação foi interrompida em banho-maria fervente. Os grupos redutores foram determinados segundo a técnica descrita por SOMOGYI modificada por NELSON [30], usando-se glicose anidra como padrão. A unidade de atividade enzimática (UAE) foi definida como sendo a capacidade da enzima em catalisar a formação de um nanomol de açúcar redutor.

\section{4 - Determinação de enzimas de escurecimento}

A extração e determinação da atividade das enzimas peroxidase (PODs) e polifenoloxidase (PFOs) foi realizada, conforme metodologia descrita por MATSUMO \& URITANI [27], sendo expressas em unidade de atividade $(0,001 \mathrm{Abs}=1$ $\mathrm{UAE}$ ) por min por $\mathrm{g}$ de tecido fresco $\left(\mathrm{U} \cdot \mathrm{min}^{-1} \cdot \mathrm{g}^{-1}\right)$.

\section{5 - Determinação de composição química}

\subsection{1 - pH e acidez total titulável}

$\mathrm{O}$ pH foi medido por meio de potenciômetro com eletrodo de vidro [3]. A acidez total titulável foi determinada por titulação do filtrado (diluição 1:5) com $\mathrm{NaOH}$ $0,1 \mathrm{~N}$, padronizado segundo técnica estabelecida pelo INSTITUTO ADOLFO LUTZ [23] e expressa em mg de ácido cítrico/100 g de tecido.

\subsection{2 - Sólidos solúveis totais}

O teor de sólidos solúveis totais (SST) foi avaliado, por meio de um refratômetro digital Atago PR-100, modelo "Palette", com compensação automática de temperatura, conforme a metodologia da AOAC [3]. Os conteúdos de SST foram expressos em ${ }^{\circ}$ Brix com precisão de $0,1{ }^{\circ}$ Brix.

\subsection{3 - Açúcares totais, redutores e não- redutores}

Os açúcares totais, redutores e sacarose foram determinados a partir de 2 g de amostra triturada e doseados pelo método descrito por SOMOGYI, adaptado por NELSON [30].

\section{6 - Avaliações físicas do fruto}

\subsection{1 - Diâmetro e comprimento}

As determinações do diâmetro e comprimento médio dos frutos ( $\mathrm{mm}$ ) foram feitas com o uso de paquímetro em 20 frutos/parcela, para cada estádio de desenvolvimento do fruto.

\subsection{2 - Peso médio}

As determinações do peso médio dos frutos (g) foram efetuadas com o uso de balança semi-analítica $(0,001 \mathrm{~g})$ em 20 frutos/parcela, para cada estádio de desenvolvimento do fruto.

\section{7 - Análise do material de parede celular (MPC)}

\subsection{1 - Extração e doseamento da parede celular}

A parede celular foi extraída do fruto inteiro, segundo metodologia de MITCHAN \& MCDONALD [28]. O tecido (200 g) em cada estádio de desenvolvimento dos frutos foi homogeneizado com etanol a $80 \%$ (200 mL). Procedeu-se, então, a filtragem em "Ktazzato" para a obtenção do resíduo e sobrenadante. O resíduo foi lavado por três vezes, com $100 \mathrm{~mL}$ de tampão fosfato $0,1 \mathrm{M}, \mathrm{pH} 7$. Ao resíduo foram adicionados $200 \mathrm{~mL}$ da mistura fenol/ácido acético/água (2:1:1, v/v/v) e o homogenato foi mantido em repouso por 20 min. Procedeu-se, então, a filtração a vácuo e lavagem do resíduo com $600 \mathrm{~mL}$ de tampão fosfato $50 \mathrm{mM}, \mathrm{pH} \mathrm{6,8}$. Posteriormente, o MPC foi lavado por três vezes, com $100 \mathrm{~mL}$ da mistura acetona e clorofórmio ( $1: 1, \mathrm{v} / \mathrm{v})$ e, finalmente, lavado com acetona P.A. O material seco em estufa a $40^{\circ} \mathrm{C}$ foi triturado em moinho tipo Wiley, utilizando malha 40 mesh e foi estocado em frascos para posterior utilização.

\subsection{2 - Composição dos açúcares neutros totais não-celulósicos}

Após a obtenção do material de parede celular (MPC), foi feita a derivatização (alditol acetato) dos açúcares neutros, seguindo as recomendações de ALBERSHEIM et al. [2].

Na determinação da hidrólise dos polissacarídeos, foram pesados $3 \mathrm{mg}$ de amostra (MPC) em tubo de ensaio rosqueado de $13 \times 10 \mathrm{~mm}$ e adicionados $500 \mu \mathrm{L}$ de ácido trifluoracético (TFA) a $2 \mathrm{~N}$, contendo $200 \mu \mathrm{g}$ de inositol/mL em black heater, vedando-se o tubo. Posteriormente, aqueceu-se o mesmo a $121^{\circ} \mathrm{C}$ por $1 \mathrm{~h}$ a seco. Após este período, o TFA foi evaporado em banho-maria a $45^{\circ} \mathrm{C}$, usando mistura de água quente e fria em becker com exaustão em capela de fluxo de ar, adicionando-se então 0,5 $\mu \mathrm{L}$ de metanol, com posterior evaporação até a secagem, operação esta repetida por três vezes.

A redução dos polissacarídeos foi determinada pela adição de $150 \mu \mathrm{L}$ de hidróxido de amônio a 1 N. Após leve mistura e manutenção em temperatura ambiente por $1 \mathrm{~h}$, foram adicionadas algumas gotas de ácido acético P.A. para a retirada do excesso de borohidreto de sódio recém-preparado, evaporando-se em banho-maria a $45^{\circ} \mathrm{C}$ com fluxo de ar, até a secagem. Em seguida, adicionou-se $500 \mu \mathrm{L}$ da mistura de metanol:ácido acético $(9: 1, v / v)$, que foi evaporada, repetindo-se esta operação por três vezes.

A acetilação dos polissacarídeos foi realizada pela adição de $150 \mu \mathrm{L}$ de anidrido acético P.A. ao tubo rosqueado. Após $3 \mathrm{~h}$ a $121^{\circ} \mathrm{C}$ em "block heater", os tubos foram 
resfriados e secos, utilizando-se banho-maria a $45^{\circ} \mathrm{C}$ e fluxo de ar nos tubos. Aplicou-se $500 \mu \mathrm{L}$ de metanol e procedeu-se a secagem da mesma forma, repetindo-se por duas vezes.

A determinação dos açúcares neutros foi feita por Cromatografia Gás-líquido, segundo a metodologia proposta por MITCHAN \& MCDONALD [28].

As amostras derivatizadas foram diluídas em $200 \mu \mathrm{L}$ de acetona e injetadas ( $2 \mu \mathrm{L})$ em cromatógrafo a gás da marca Varian, modelo 3.800, conectado a um work station, versão Varian Star 4.5, coluna capilar com fase ligada OV-DB-225 com $30 \mathrm{~m}$ de comprimento e $0,25 \mathrm{~mm}$ de diâmetro interno (30 m x 0,25 mm: 0,25 $\mu \mathrm{m}$ ), DIC/detector de ionização de chamas.

Foi utilizado o hidrogênio como gás de queima, o ar sintético para manter a chama e o make up, uma mistura de hidrogênio e nitrogênio (30 mL/min.) como gás de arraste.

A pressão na coluna foi de $24 \mathrm{psi}$, com fluxo de 1,3 mL.min ${ }^{-1}$, make-up de $30 \mathrm{~mL} \cdot \mathrm{min}^{-1}, \mathrm{H}_{2}$ a 34,5 mL.min ${ }^{-1}$ e ar a $300 \mathrm{~mL} \cdot \mathrm{min}^{-1}$. A sensibilidade utilizada foi de $10^{-11} \mathrm{e}$ atenuação 1. As temperaturas da coluna, injetor e detector foram, respectivamente, $210^{\circ} \mathrm{C}, 250^{\circ} \mathrm{C}$ e $300^{\circ} \mathrm{C}$.

Utilizou-se como padrão uma mistura de ramnose, fucose, arabinose, xilose, manose, galactose, glucose e inositol, todos na concentração de $50 \mu \mathrm{g}$ e igualmente derivatizados.

\subsection{3 - Celulose, hemicelulose e pectina total}

A concentração de celulose foi determinada pelo método de Antrona, segundo DISCHE [12], após digestão de $2 \mathrm{mg}$ de parede celular em $3 \mathrm{~mL}$ de $\mathrm{H}_{2} \mathrm{SO}_{4} 72 \%$ por $12 \mathrm{~h}$. Os resultados foram expressos em percentagem de celulose na parede celular.

Quanto à hemicelulose, foi feita a solubilização de 2 mg de parede celular em $1 \mathrm{~mL}$ de ácido trifluoracético (TFA $2 \mathrm{~N}$ ) a $120^{\circ} \mathrm{C}$ por $1 \mathrm{~h}$, diluídos em $50 \mathrm{~mL}$ de água destilada e filtrados em papel de filtro. Os resultados foram expressos em percentagem de hemicelulose na parede celular.

Para a determinação da pectina total, foram digeridos $2 \mathrm{mg}$ de parede celular em $3 \mathrm{~mL}$ de $\mathrm{H}_{2} \mathrm{SO}_{4} 67 \%$ por $12 \mathrm{~h}$, e o teor de ácidos urônicos foi doseado pelo método do carbazol [7]. Os resultados foram expressos em percentagem de pectina na parede celular.

\section{8 - Delineamento experimental e análise estatística}

O experimento foi conduzido em delineamento inteiramente casualizado (DIC), composto de cinco tratamentos (Tabela 1), duas repetições, totalizando dez parcelas, com a obtenção de $500 \mathrm{~g}$ de fruto/parcela. Foi feita análise de regressão para todos os parâmetros.
TABELA 1 - Relação dos tratamentos em cada estádio de desenvolvimento dos frutos. Ufla, Lavras, 2005

\begin{tabular}{lc}
\hline Tratamentos & $\begin{array}{c}\text { Estádio de desenvolvimento dos } \\
\text { frutos (dias) }\end{array}$ \\
\hline 1 (Fruto não diferenciado) & $15^{*}$ \\
2 (Fruto verde diferenciado) & $30^{\star}$ \\
3 (Fruto verde amarelado) & $45^{\star}$ \\
4 (Fruto amarelo arroxeado) & $60^{\star}$ \\
5 (Fruto arroxeado) & $75^{\star}$ \\
\hline
\end{tabular}

*Dias após a diferenciação da gema em sicônio

\section{3 - RESULTADOS E DISCUSSÃO}

\section{1 - Enzimas: polifenoloxidase (PFO), peroxidase (POD), pectinametilesterase (PME) e poligalacturonase $(\mathbf{P G})$}

Conforme os resultados apresentados nas Figuras 1 e 2, as equações que se ajustaram melhor durante a evolução da atividade enzimática nos diferentes estádios de desenvolvimento dos frutos de figueira foram linear (PFO e PG), quadrática (POD) e cúbica (PME).

À medida que a atividade enzimática de PFO e POD foi diminuindo, observou-se um aumento significativo da atividade da PG, no decorrer do desenvolvimento dos frutos, que atingiram a maturidade fisiológica aos 75 dias (Figura 1). Portanto, a maior atividade da peroxidase e polifenol-oxidase ocorreu nos frutos verdes.

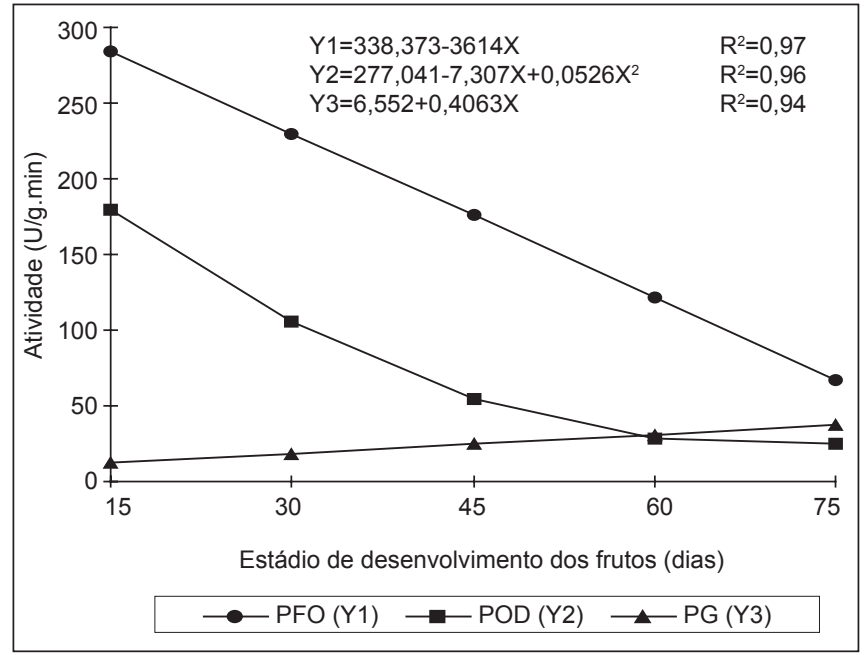

FIGURA 1 - Atividade das enzimas polifenoloxidase (PFO), peroxidase (POD) e poligalacturonase (PG) nos diferentes estádios de desenvolvimento dos frutosde figueira (Ficus carica L.), durante o ano agrícola 2001/2002. DCA/Ufla, Lavras (MG), 2005

A maior atividade da POD na fase inicial de desenvolvimento dos frutos pode ser explicada pela sua função metabólica de proteger os tecidos vegetais contra os efeitos tóxicos do peróxido de hidrogênio durante o metabolismo celular. Porém, BURNETTE [9] cita que a maior função desta enzima é a de catalisar a oxidação álcool-coniferil, para 
formar radicais fenólicos que, em seguida, polimerizamse para formar a lignina (polímero que contribui para o fortalecimento mecânico da célula).

Quanto à PFO, dentre as numerosas funções supostas ou comprovadas desta enzima, a principal é sua contribuição à resistência das plantas contra vírus e microorganismos, principalmente na fase inicial de desenvolvimento dos frutos. Com efeito, as quinonas produzidas provocam reações secundárias de polimerização, levando à formação de polímeros escuros e insolúveis nas células. Estes polímeros têm um papel de barreira contra os microorganismos externos [28]. À medida que o fruto vai amadurecendo, a atividade desta enzima diminui, em função das alterações na estrutura de parede.

Observou-se uma pequena atividade de PME (Figura 2) no fruto até os 30 dias, havendo, a partir daí, um aumento significativo de sua atividade, atingindo o máximo de atividade aos 60 dias. $\mathrm{O}$ aumento da atividade desta enzima resulta em diminuição no grau de esterificação, demonstrando sua efetividade em desmetilar o polímero péctico para a ação subsequente da PG. A partir dos 60 dias, a atividade de PME tendeu a decrescer. A pequena atividade na fase inicial do fruto pode ser explicada pelo fato deste ainda não ter se diferenciado completamente. Aos 60 dias, o fruto já está próximo da maturidade fisiológica e a enzima já atuou de forma efetiva, preparando as subunidades de protopectina, aumentando a atividade da PG (Figura 1). Comportamento semelhante foi observado em frutos de goiaba [21] e manga [14]. Segundo AWAD (1993), a atividade de PME pode aumentar, diminuir ou permanecer constante durante a maturação, dependendo do tipo de fruto.

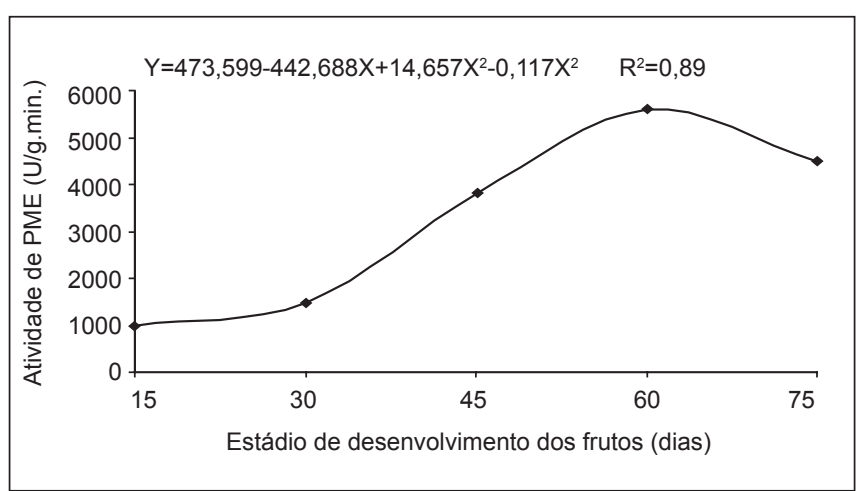

FIGURA 2 - Atividade da enzima pectinametilesterase (PME) nos diferentes estádios de desenvolvimento dos frutos de figueira (Ficus carica L.), durante o ano agrícola 01/02. DCA/Ufla, Lavras (MG), 2005

\section{2 - Composição química}

Conforme observado na Figura 3, os teores de sólidos solúveis totais (SST) apresentaram um aumento quadrático ascendente, atingindo um teor máximo de $13^{\circ} \mathrm{Brix}$ para frutos maduros (75 dias). Este valor do Brix aos 75 dias está de acordo com HERNANDES et al. [20], KOYUNCU et al. [25] e PENTEADO [34]. Os valores de SST em frutos podem variar em função da cultivar, das condições edafoclimáticas e da época de colheita [10].

Observou-se também um aumento dos açúcares solúveis totais (AT) que variaram de 3,24\% (15 dias) a 11,37\% (75 dias). SAAD et al. [37] encontraram de $14,08 \%$ a $18,73 \%$ de AT na fase final de crescimento do fruto.

WHITING [41] afirma que o conteúdo de açúcares aumenta gradativamente durante os primeiros estádios de desenvolvimento do fruto e rapidamente nos últimos estádios de maturação, dependendo da cultura. No decorrer do amadurecimento, ocorrem a hidrólise do amido, a transformação dos constituintes celulósicos e a conversão de protopectina em pectina solúvel.

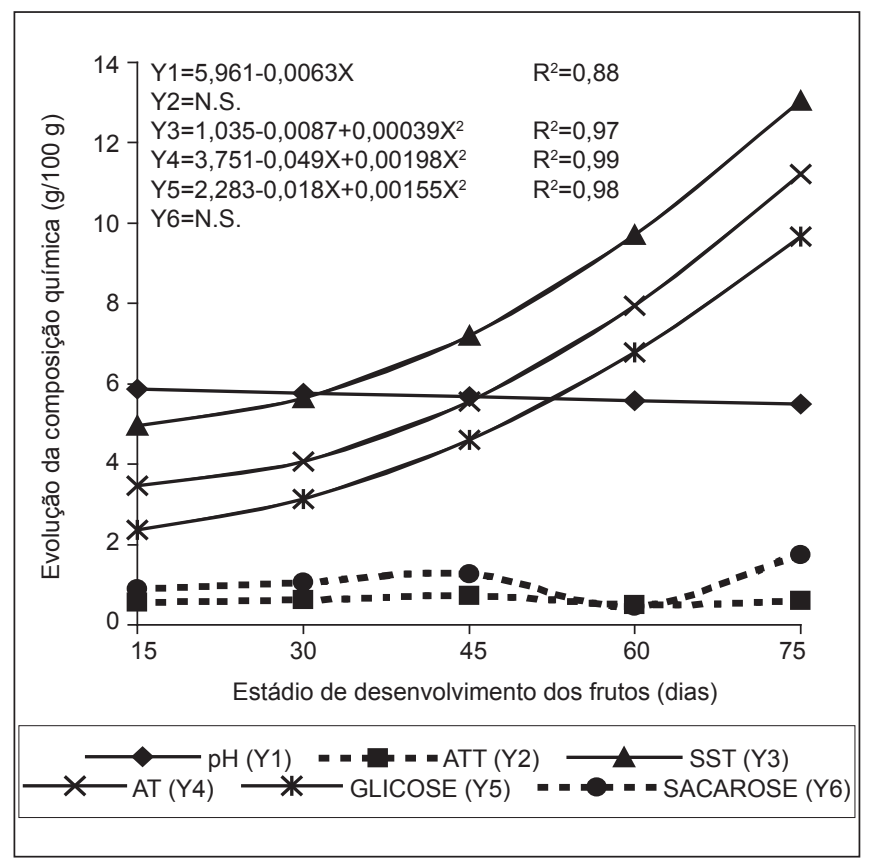

FIGURA 3 - Evolução dos teores de pH, acidez total titulável (ATT), sólidos solúveis totais (SST), açúcares solúveis totais (AT), açúcares redutores (glicose) e açúcares não-redutores (sacarose) nos diferentes estádios de desenvolvimento dos frutos de figueira (Ficus carica L.) durante o ano agrícola 2001/2002. DCA/Ufla, Lavras (MG), 2005

Quanto aos açúcares redutores (glucose), os valores foram menores do que os dos açúcares solúveis totais, atingindo um máximo de 9,51\% aos 75 dias e bem superiores aos açúcares não-redutores (sacarose), que apresentaram valores inferiores a $1,75 \%$, estando de acordo com CHESSA [11] e TSANTILI [39]. Ao contrário, SAAD et al. [37] observaram maior \% de sacarose em relação à glicose, durante o amadurecimento de figos que sofrem polinização.

Observou-se uma tendência de queda linear do $\mathrm{pH}$, com a evolução do amadurecimento dos frutos, variando de 5,91 a 5,45, estando de acordo com KOYUNCU et al. [25]. Essas pequenas variações de $\mathrm{pH}$ podem ser atri- 
buídas ao efeito tamponante ocasionado pela presença simultânea de ácidos orgânicos e de seus sais, o que faz com que alterações na ATT não afetem significativamente os valores de $\mathrm{pH}[26]$.

Quanto à acidez total titulável (ATT) e à sacarose, não houve ajuste da equação de regressão. Observou-se que os valores de ATT foram baixos e com pequenas variações no decorrer dos estádios de desenvolvimento dos frutos (0,55 a 0,72\%). KOYUNCU et al. [25] também obtiveram valores de ATT baixos (0,13-0,34\%). Ao contrário, CHESSA et al. [11] observaram um aumento da ATT na fase inicial de desenvolvimento dos frutos de figo da cv. Rampelina e declínio no final do desenvolvimento.

\section{3 - Atributos físicos}

Conforme os resultados apresentados nas Figuras 4 e 5 , as equações que se ajustaram melhor durante a evolução dos atributos físicos nos diferentes estádios de desenvolvimento dos frutos de figueira foram linear ascendente (diâmetro e comprimento médio dos frutos) e quadrática ascendente (peso médio dos frutos).

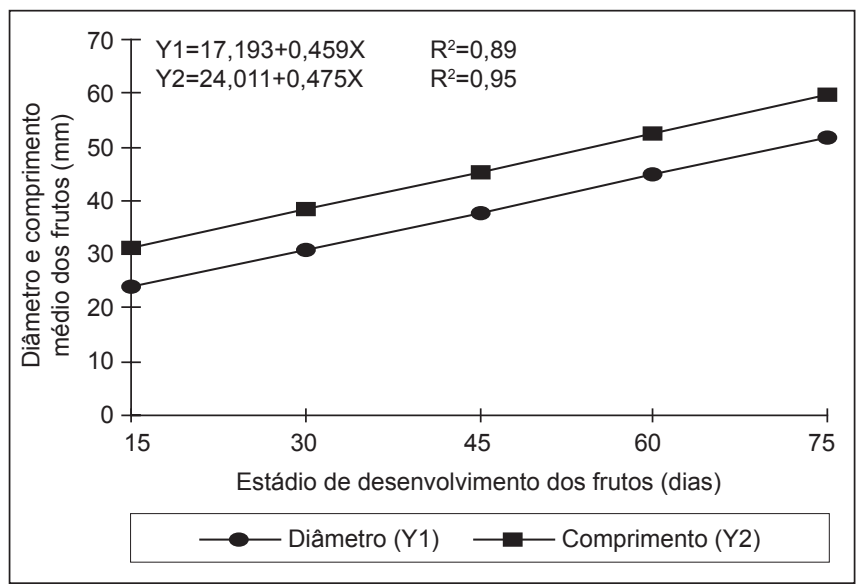

FIGURA 4 - Evolução do diâmetro e comprimento médio nos diferentes estádios de desenvolvimento dos frutos de figueira (Ficus carica L.), durante o ano agrícola 2001/2002. DCA/Ufla, Lavras (MG), 2005

O diâmetro médio dos frutos foi sempre inferior ao comprimento médio, apresentando, no primeiro estádio de desenvolvimento ( 15 dias), 24,74 mm, atingindo 51,99 $\mathrm{mm}$ aos 75 dias, quando os frutos já se apresentavam totalmente maduros. Este resultado está de acordo com o descrito por PENTEADO [34], que obteve um diâmetro variando de 53,57 a 54,93 mm no fruto maduro. Já o comprimento médio dos frutos iniciou com 32,29 $\mathrm{mm}$ aos 15 dias, atingindo 59,18 $\mathrm{mm}$ aos 75 dias. HERNANDEZ et al. [20], avaliando plantas com 12 ramos, na terceira colheita de frutos maduros, observaram médias de comprimento de frutos variando de 42,9 a 52,9 mm e diâmetro de 39,8 a $47 \mathrm{~mm}$, valores bem inferiores ao presente trabalho e aos relatados por PEREIRA [35], que descreveu frutos com comprimento de $75 \mathrm{~mm}$. Isto se deve ao fato de os estudos terem sido realizados em condições edafoclimáticas diferentes, tendo a planta um comportamento característico para cada região.

Os frutos verdes no ponto de colheita para a indústria, aos 30 dias após a diferenciação das gemas em sicônio, apresentaram diâmetro $33,37 \mathrm{~mm}$ e comprimento de $38,30 \mathrm{~mm}$, estando de acordo com NORBERTO et al. [32], que obtiveram frutos com diâmetro variando de 28,3 a $30,9 \mathrm{~mm}$, oriundos de poda no mês de junho, sob irrigação. Para os frutos destinados ao consumo in natura, aos 75 dias eles se apresentaram com diâmetro de 51,99 mm e comprimento de $59,18 \mathrm{~mm}$. Vale ressaltar que não foi feito nenhum tipo desbaste de frutos. Observa-se que frutos de figueira numa região mais quente tendem a apresentar maiores valores de comprimento e diâmetro durante o seu desenvolvimento.

O conhecimento da curva de crescimento do figo é de fundamental importância, tanto para frutos verdes quanto para maduros, uma vez que o produtor, sabendo qual o período de tempo necessário para se atingir um determinado estádio de desenvolvimento, pode planejar suas atividades, tais como pulverizações (período de carência), ensacamento do fruto e ponto de colheita.

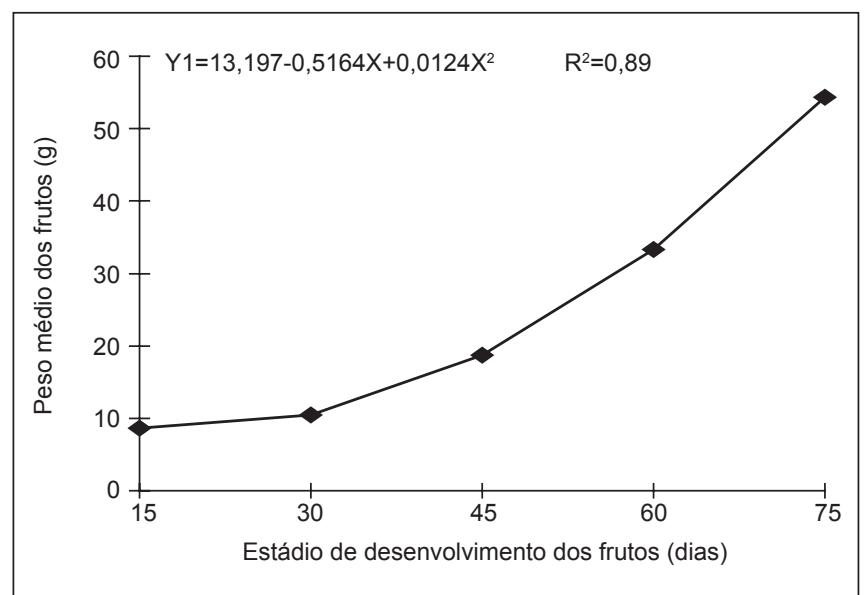

FIGURA 5 - Evolução do peso médio nos diferentes estádios de desenvolvimento dos frutos de figueira (Ficus carica L.), durante o ano agrícola 2001/2002. DCA/Ufla, Lavras (MG), 2005

Observou-se um peso médio dos frutos de 7,63 g na fase inicial de desenvolvimento (15 dias), atingindo 53,23 g quando eles se apresentavam totalmente maduros (75 dias). Este resultado está de acordo com PEREIRA [35], que obteve um peso médio de 47 a $52,6 \mathrm{~g}$ para frutos maduros. Já EL-KASSAS et al. [13] e KOYUNCU et al. [25] obtiveram peso médio de frutos maduros em torno de 11,8 a 40 g para as cv. Kahramani e Abiad Mission e 9 a 38,4 $\mathrm{g}$, durante o desenvolvimento de figos cultivados em nove locais diferentes.

\section{4 - Açúcares neutros da parede celular}

Como se observa na Figura 6, os açúcares neutros determinados através de Cromatografia Gasosa predo- 
minantes foram a xilose, arabinose e a galactose. Com a maturação dos frutos, houve perda líquida dos principais componentes dos polissacarídeos pécticos (galactose, arabinose), embora a ramnose tenha apresentado um aumento em seu teor dos 30 aos 60 dias, com posterior queda, indicando a síntese de poliuronídeos mais ramificados e com cadeias laterais mais volumosas. O comportamento semelhante da galactose e da arabinose sugere que estes açúcares foram provenientes da hidrólise arabinogalactana. Quanto aos componentes da fração hemicelulósica (xilose, glicose e manose), eles tenderam a aumentar. Os açúcares fucose, manose, glicose e ramnose foram aqueles presentes em menor quantidade na parede celular durante os diferentes estádios de desenvolvimento dos frutos de figueira Ficus carica $L$.

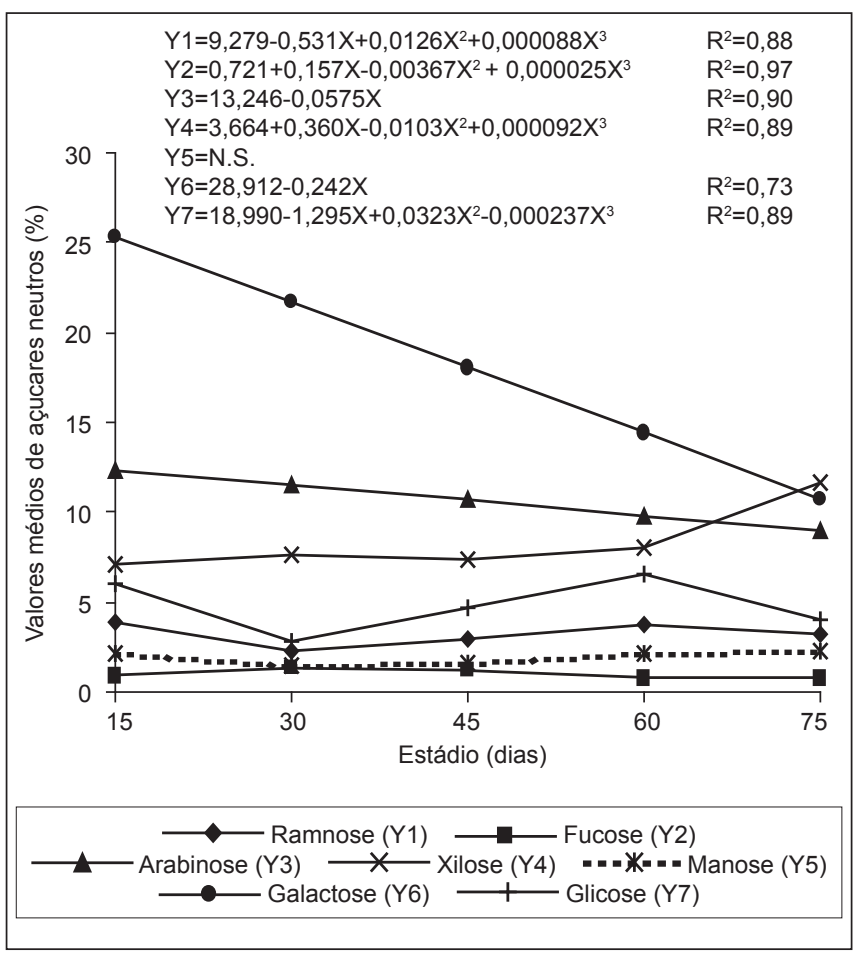

FIGURA 6 - Resíduos de açúcares neutros não-celulósicos nos diferentes estádios de desenvolvimento dos frutos de figueira (Ficus carica L.), durante o ano agrícola 2001/2002. DCA/Ufla, Lavras (MG), 2005

A solubilização de polímeros pécticos e a perda de açúcares neutros não-celulósicos têm sido relatadas durante o amadurecimento de manga [8], [28]; de pêra [2]; e de tomate [19]. No entanto, durante o processo de amadurecimento, podem ocorrer reações degradativas, mas também de síntese, conforme FISCHER et al. [16], MITCHAN \& McDONALD [28] e VILAS BOAS et al. [40].

As alterações na composição da parede celular demonstram a maior sensibilidade dos frutos maduros à degradação pelas enzimas hidrolíticas, pela dissolução da lamela média, bem como pela degradação da parede celular, levando a uma perda da coesão do tecido, percebido com o amaciamento [22].
As modificações dos açúcares neutros observadas sugerem um turnover, ou seja, um metabolismo dinâmico na parede celular dos frutos de figueira durante a sua maturação. O amadurecimento de muitos frutos é marcado por um incremento na solubilização de substâncias pécticas [6] e perda líquida de açúcares neutros não-celulósicos [18]. As mudanças na estrutura hemicelulósica associadas ao amadurecimento são importantes na determinação das mudanças texturais dos frutos, embora as bases bioquímicas do turnover hemicelulósico ainda não estejam caracterizadas [16].

O comportamento dos açúcares neutros não-celulósicos e demais compostos da parede celular de frutos de figueira Ficus carica $L$. durante o amadurecimento ainda não foi pesquisado, impossibilitando comparações específicas dos resultados obtidos no presente estudo.

\section{5 - Compostos de parede celular}

Conforme os resultados apresentados na Figura 7, as equações que se ajustaram melhor durante a evolução dos compostos de parede celular nos diferentes estádios de desenvolvimento dos frutos de figueira foram a quadrática (pectina total) e cúbica (celulose e hemicelulose).

O teor de pectina total durante o desenvolvimento do fruto de figueira apresentou-se com 26,86\% (15 dias), aumentando gradativamente até atingir 34,72\% (45 dias). A partir daí, houve um decréscimo de seu teor, atingindo 28,5\% aos 75 dias (Figura 7). O aumento dos teores de pectina total, até os 45 dias, pode ser explicado pelos íons cálcio que se associam ao ácido poligalacturônico, formando pectados de cálcio, conferindo maior rigidez ao tecido vegetal. A redução na porcentagem de pectina total a partir dos 45 dias coincide com a intensa atividade da PME e PG e conseqüente aumento na solubilização das pectinas (Figuras 1 e 2 ).

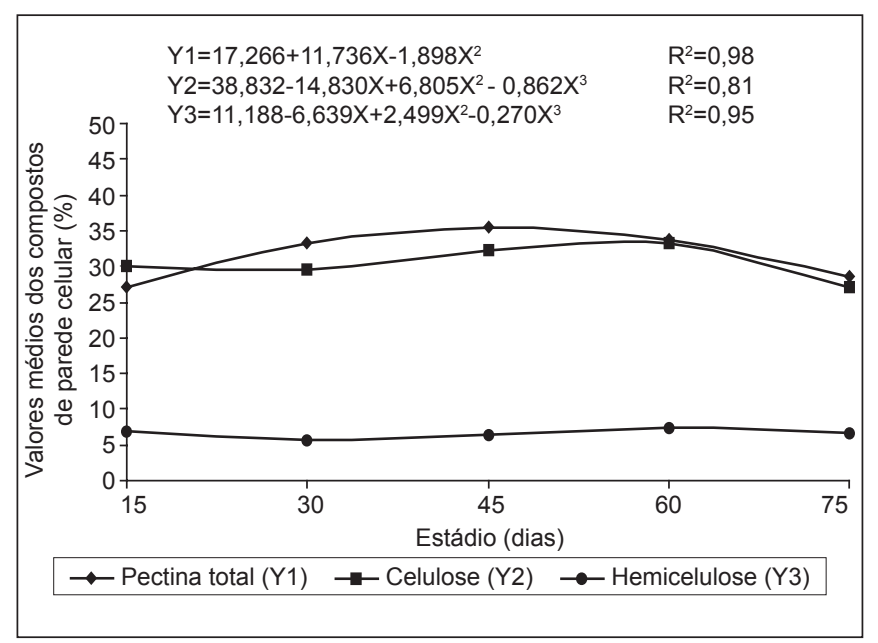

FIGURA 7 - Compostos de parede celular nos diferentes estádios de desenvolvimento dos frutos de figueira (Ficus carica L.) durante o ano agrícola 2001/2002. DCA/Ufla, Lavras (MG), 2005 
Quanto à celulose, observou-se um teor de $29,65 \%$, que se manteve estável até os 30 dias $(30,64 \%)$. A partir dos 30 dias houve um aumento gradativo do teor de celulose, atingindo o máximo de $34 \%$ aos 60 dias, seguido de queda de até $26,69 \%$ aos 75 dias. Observou-se, portanto, que a redução nos teores de celulose se deu a partir dos 60 dias, quando o fruto, já na maturidade fisiológica, inicia o processo de amaciamento, em função da solubilização de pectinas, pela maior atividade das enzimas PME e PG. A degradação de compostos celulósicos envolve a ação hidrolítica de várias enzimas que catalisam a quebra das ligações glicosídicas $\beta(1,4)$ entre resíduos de D-glucose da molécula de celulose ou de seus derivados solúveis. Isto requer um complexo celulolítico envolvendo as enzimas celulase, endoglucanase, exoglucosidase e $\beta$-glucosidase [37]. BABBIT et al. [5] propuseram que, possivelmente, o amaciamento de frutos se inicie pela ação de celulases no entrelaçamento das microfibrilas, possibilitando que outras enzimas, inclusive a PG, tenham acesso a seus substratos.

A hemicelulose é um polissacarídeo heterogêneo constituído por açúcares neutros que interagem com a celulose e as substâncias pécticas. Pela Figura 7, observa-se que os teores de hemicelulose durante o desenvolvimento do fruto da figueira apresentaram-se bem mais baixos que os de celulose e pectina total, com percentuais de $6,81 \%$ aos 15 dias, apresentando pequena queda até atingir 5,62\%, aos 30 dias. A partir daí, observou-se um aumento gradativo em seu teor, atingindo um máximo de $7,19 \%$ aos 60 dias e posterior queda para $6,71 \%$ aos 75 dias. Esta queda no teor de hemicelulose a partir dos 60 dias, que coincide com a queda dos teores de celulose e pectina total, pode ser explicada pelo fato das fibrilas de celulose serem unidas por pontes de hidrogênio responsáveis pela interação de celulose com hemicelulose, segundo FRY [17].

A solubilização de polímeros pécticos e a perda de açúcares neutros não-celulósicos têm sido relatadas durante o amadurecimento de manga [8, 28] e pêra [2]. Porém, durante o processo de amadurecimento podem ocorrer não somente reações degratativas, mas também de síntese, conforme verificaram FISCHER et al. [15] e VILAS BOAS [40].

\section{4 - CONCLUSÕES}

A atividade de polifenoloxidase e peroxidase diminuiu e a atividade da poligalacturonase aumentou, no decorrer do desenvolvimento dos frutos de figueira.

O ponto de colheita para a indústria e consumo in natura se deu aos 30 dias $(38,30 \mathrm{~mm}$ de comprimento e $33,37 \mathrm{~mm}$ de diâmetro) e 75 dias $(59,18 \mathrm{~mm}$ de comprimento e 51,99 mm de diâmetro) após a diferenciação das gemas em sicônio, respectivamente.

TABELA 2 - Resumo da análise de variância para as variáveis: sólidos solúveis totais (SST), potencial hidrogeniônico (pH), acidez total titulável (ATT), açúcares totais (AT), glucose (G), sacarose (S), diâmetro dos frutos (DF), comprimento dos frutos (CF) e peso dos frutos (PF), em diferentes estádios de desenvolvimento dos frutos de figueira Ficus carica L., durante o ciclo agrícola 2001/2002. Ufla, Lavras (MG), 2003

\begin{tabular}{lcccccccccc}
\hline & & \multicolumn{10}{c}{ Quadrados médios } \\
\cline { 2 - 11 } C.V. & G.L. & SST & pH & ATT & AT & G & S & DF & CF & PF \\
\hline Estádio & 4 & $0,905^{*}$ & $0,07^{*}$ & $0,014^{*}$ & $20,495^{*}$ & $17,907^{*}$ & $0,4523^{*}$ & $265,48^{*}$ & $268,69^{*}$ & $766,44^{*}$ \\
Resíduo & 5 & 0,007 & 0,005 & 0,003 & 0,0439 & 0,0028 & 0,0444 & 0,1583 & 1,0781 & 1,1798 \\
\hline C.V. $(\%)$ & & 5,42 & 1,28 & 9,86 & 3,25 & 1,01 & 16,15 & 1,05 & 2,29 & 4,32 \\
\hline
\end{tabular}

TABELA 3 - Resumo da análise de variância para as variáveis polifenol-oxidase (PFO), pectinametilesterase (PME), poligalacturonase (PG) peroxidase (POD), celulose (C), hemicelulose (H) e pectina total (PT), em diferentes estádios de desenvolvimento dos frutos de figueira Ficus carica L., durante o ciclo agrícola 2001/2002. Ufla, Lavras (MG), 2003

\begin{tabular}{|c|c|c|c|c|c|c|c|c|}
\hline \multirow[b]{2}{*}{ C.V. } & \multirow[b]{2}{*}{ G.L. } & \multicolumn{7}{|c|}{ Quadrados médios } \\
\hline & & PFO & PME & PG & POD & C & $\mathrm{H}$ & PT \\
\hline Estádio & 4 & $15070,40^{*}$ & $8724647,15^{*}$ & $198,68^{*}$ & $8778,55^{*}$ & $22,43^{*}$ & $1,0312^{*}$ & $39,519^{\prime}$ \\
\hline Resíduo & 5 & 461,8 & 314627,83 & 82,12 & 77,97 & 1,288 & 0,0158 & 0,4391 \\
\hline
\end{tabular}

TABELA 4 - Resumo da análise de variância para as variáveis ramnose (RA), arabinose (ARA), xilose (XIL), manose (MAN), galactose (GAL), glucose (GLU) e fucose (FUC), em diferentes estádios de desenvolvimento dos frutos de figueira Ficus carica L., durante o ciclo agrícola 2001/2002. Ufla, Lavras (MG), 2003

\begin{tabular}{lcccccccc}
\hline & & \multicolumn{7}{c}{ Quadrados médios } \\
\cline { 2 - 8 } C.V. & G.L. & RA & ARA & XIL & MAN & GAL & GLU \\
\hline Estádio & 4 & $1,8572^{*}$ & $8,2046^{*}$ & $15,4426^{*}$ & 0,4796 NS & $181,204^{*}$ & $10,4116^{*}$ & 0,2259 NS \\
Resíduo & 15 & 0,1988 & 6,2806 & 1,1529 & 0,6651 & 75,736 & 2,984 & 0,1141 \\
\hline C.V. $(\%)$ & & 13,91 & 23,52 & 12,82 & 41,47 & 48,27 & 35,73 & 33 \\
\hline
\end{tabular}


Ocorreu um aumento significativo nos teores de sólidos solúveis totais, açúcares solúveis totais e redutores, durante o desenvolvimento do fruto, tendo a sacarose apresentado níveis mais baixos.

O pH e a ATT apresentaram pouca variação durante o desenvolvimento do fruto.

O diâmetro, o comprimento e o peso médio dos frutos atingiram 51,99 $\mathrm{mm}, 59,18 \mathrm{~mm}$ e 53,23 g, respectivamente, aos 75 dias.

Os açúcares neutros predominantes foram a galactose, a arabinose e a xilose, enquanto fucose, manose e glucose e ramnose foram aqueles presentes em menor quantidade na parede celular durante os diferentes estádios de desenvolvimento dos frutos.

Com a maturação dos frutos, houve redução dos principais componentes dos polissacarídeos pécticos (galactose, arabinose e ramnose), enquanto os componentes da fração hemicelulósica (xilose, glucose e manose) aumentaram.

A solubilização da celulose e queda nos teores de hemicelulose se deu a partir dos 60 dias.

\section{5 - REFERÊNCIAS BIBLIOGRÁFICAS}

[1] ABRAHÃO, E.; ANTUNES, L.E.C.; SILVA, V.J.S.da. Poda e condução da figueira. Informe Agropecuário. Belo Horizonte, v. 18, n. 188, p. 6-13, 1997.

[2] AHMED, A.E.; LABAVITCH, J.M. Cell wall metabolism in ripening fruit 1 . Cell wall changes in ripening barblett 'pears'. Plant Physiology. Baltimore, v. 65, n. 5, p. 1.009-1.013, May, 1980.

[2] ALBERSHEIN, P.; NEVINS, D.J.; ENGLISH, P.D. A method for the analysis of sugar in plant cell wall polysaccharides by gas-liquid chomatography. Carbohydrate Research. Amsterdan, v.5, p.340-345, 1967.

[3] ASSOCIATION OF OFFICIAL ANALYTICAL CHEMISTRY. Official methods of analysis of the Association of Official Analytical Chemistry. $12^{\text {th }}$ ed., Washington, 1992.

[4] AWAD, M. Fisiologia pós-colheita de frutos. São Paulo, Nobel, 114 p., 1993.

[5] BABBIT, J.K.; POWERS, M.J.; PATTERSON, M.E. Effects of growth regulators on cellulase, polygalacturonase, respiration, color and texture of ripening tomatoes. Journal of the American Society for Horticultural Science. Alexandria, v. 98, n. 1, p. 77-81, Jan. 1973.

[6] BARTLEY, I.M.; KNEE, M. The chemistry of textural changes in the fruit during storage. Food Chemistry. Essex, v .9, p. 47-58, 1982.

[7] BITTER, V.; MUIR, H.M.A. A modified uronic acid caarbazole reaction. Analytical Biochemistry. New York, v. 34, p. 330-334, 1962.

[8] BRINSON, K.; DEY, P.M.; JOHN, M.A.; PRIDHAM, J.B. Post-harvest changes in Mangífera indica mesocarp cell walls and cytoplasmic polysaccharides. Phytochemistry. Oxford, v. 27, n. 3, p. 719-723, 1988.

[9] BURNETTE, F.S. Peroxidase and its relationship to food flavor and quality: a review. Journal of Food Science, v. 42, n. 1, p. 1-6, 1977.

[10] CARVALHO, H.A. de. Utilização de atmosfera mo- dificada na conservação pós-colheita da goiaba kumagai. 1999. 115 p. Dissertação (mestrado em Ciência dos Alimentos) - Universidade Federal de Lavras, Lavras.

[11] CHESSA, I.; NIEDDU, G.; SCHIRRA, M. Growth and ripening of main-crop fig. Advances in horticultual science. Sassari, v. 6, n. 3, p. 112-115, 1992.

[12] DISCHE, Z. Color reaction of carbohydrates. In: WHISTLER, R.L.; WOLFRAN, M.L. Methods in carbohidrates chemistry. New York, Academic, v. 1, p. 477-512, 1962.

[13] El-KASSAS, S.E. et al. Evaluation of some introduced and local fig cultivars under Assiut climatic condictions. Assiut Journal of Agricultural Sciences. Assiut, v. 23, n. 2, p. 305-319, 1992.

[14] EL-ZOGHBI, M. Biochemical changes in some tropical fruits during ripening. Food Chemistry. London, v. 49, n. 1, p. 33-37, Jan. 1994.

[15] FISHER, M.; ARRIGONI, E.; AMADO, R. Changes in pectic substances of apples during development and post harvest ripening. Part. 2: Analysis of the pectic fractions. Carbohydrate Polymers. London, v. 25, p. 167-175, 1994.

[16] FISCHER, R.L.; BENNET, A.B. Role of cell wall hydrolases in fruit ripening. Annual Review of Plant Molecular Biology. Palo Alto, v. 675-710, 1991.

[17] FRY, S.C. Cross-linking of matrix polymers in the griwing cell walls of angiosperms. Annual Review of Plant Physiology. Palo Alto, v. 37, p. 165-186, 1986.

[18] GROSS, K.C.; SAM, C.E. Changes in cell wall neutral composition during fruit ripening: a species survey. Phytochemistry. Great Britain, v. 23, n. 11, p. 2.4572.461, Nov. 1984.

[19] GROSS, K.C.; WALLNER, S.J. Degradation of cell wall polysaccharides during tomato fruit ripening. Plant Physiology. Baltimore, v. 63, n. 1, p. 117-120, Jul. 1979.

[20] HERNANDES, F.B.T. et al. Effects of irrigation and nitrogen levels on qualitative and nutritional aspects of fig- trees (Ficus carica L.). Science Agriculturae. Piracicaba, v. 51, n. 2, p. 292-297, May/Aug. 1994.

[21] HUSSAIN, A.; SHAH, A.H. Activity of pectic enzymes (pectinesterase and polygalacturonase) during the ripening of guava fruit. Pakistan Journal of Agricultural Sciences. Lyallpur, v. 5, p. 191-194, 1975.

[22] HUYSAMER, M.; GREVE, L.C.; LABAVITCH, J.M. Cell wall metabolism in ripening fruit. VIII. Cell wall composition and synthetic capacity of two regions of the outer pericarp of mature green and red ripe cv. Jackpot Tomatoes. Physiologia Plantarum. Copenhagen, v. 1 01, n. 2, p. 314-322, Oct. 1997.

[23] INSTITUTO ADOLFO LUTZ. Normas analíticas, métodos químicos e físicos para análise de Alimentos. $3^{\mathrm{a}}$ ed., São Paulo, v. 1, 533 p., 1985.

[24] JEN, J.J.; ROBINSON, M.L.P. Pectinolytic enzymes in sweet bell peppers (Capsicum annuum L.). Journal of Food Science. Chicago, v. 49, p. 1.045-1.087, 1984.

[25] KOYUNCU, M.A. et al. A study on some caracteristics in local fig cultivars grown in Hilvan. Acta Horticulturae. Izmir, n. 480, p. 83-85, 1998.

[26] LEHNINGER, A.L. Princípios de bioquímica. São Paulo, Sarvier, 725 p., 1990. 
[27] MATSUMO, H.; URITANI, I. Physiological behavior of peroxidase isosymes in sweet potat root, tissue injured by cuting or black rot. Plant and Cell Physiology. Kamikyo-Ku, v. 13, n. 6, p. 1.091-1.101, 1972.

[28] MITCHAN, E.J.; McDONALD, E.E. Cell wall modification during ripening of 'Keith' and 'Tommy Atkins' mango fruit. Journal of American Society for Horticulturae Science. Alexandria, v. 117, n. 6, p. 919-924, 1992.

[29] MONDY, N.I.; KOCH, R.L. Effect of potato virus X on enzymatic darketing and lipid content potatoes. Journal of Food Science. v. 43, p. 703, 1978.

[30] NELSON, N. A photometric adaptation os Somogyi method for determination of glicose. Journal of Biological Chemistry. Baltimore, v. 135, n. 1, p. 136-175, Jan. 1944.

[31] NOGUEIRA, A.M.M. Propagação da figueira (Ficus carica $L$.) através de estacas caulinares em casa de vegetação. 1995. 61 p. Dissertação (mestrado em Fitotecnia) - Universidade Federal de Lavras, Lavras.

[32] NORBERTO, P.M.; CHALFUN, N.N.J.; PASQUAL, M. Efeitos da época de poda, cianamida hidrogenada e irrigação na produção antecipada de figos verdes. Pesquisa Agropecuária Brasileira. Brasília, v. 36, n. 11 , p. 1.363-1.369, nov. 2001.

[33] PEDROTTI, E.L. Níveis de irrigação, crescimento das plantas e concentração de nutrientes nas folhas da figueira (Ficus carica L.) 'roxo de Valinhos'. 1982. 88 p. Dissertação (mestrado em Fitotecnia) - Universidade Federal do Rio Grande do Sul, Porto Alegre.

[34] PENTEADO, S.R. Fruticultura de clima temperado em São Paulo. Campinas, Fundação Cargill, 173 p., 1986.

[35] PEREIRA, F.M. Cultura da figueira. São Paulo, Livroceres, 73 p., 1981.

[36] PRESSEY, R.; AVANTS, J. K. Separation and characterization the exopolygalacturonase e endopolygalacturonase from peaches. Plant Physiology. Baltimore, v. 52, n. 3, p. 252-256, Sep. 1973.
[37] SAAD, F.A.; BACHA, M.A.; ABO-HASSAN, A.A. Preliminary studies on fruit characteristics of four fig cultivars grow at Riyadh, Saudi Arabia. Journal of the College of Agriculture. Riyadh, v. 1, p. 97-103, 1979.

[38] SILVA, R.; FRANCO, C.M.L.; GOMES. E. Pectinases, hemicelulases e celulases, ação, produção e aplicação no processamento de alimentos: revisão. Boletim da Sociedade Brasileira de Ciência e Tecnologia de Alimentos. Campinas, v. 31, n. 2, p. 249-260, jul./dez. 1997.

[39] TSANTILI, E. Changes during development of Tsapela fig fruits. Scientia Horticulturae. Athens, v. 44, n. 3/4, p. 227-234, 1990.

[40] VILAS BOAS, E.V. de B. et al. Modificações texturais de tomates heterozigotos no loco alcobaça. Pesquisa Agropecuária Brasileira. Brasília, v. 35, n. 7, p. 1.4471.453, 2000.

[41] WHITING, G. Sugars. In: The biochemistry of fruits and their products. London, Academic, v. 1, p. 1-37, 1970.

\section{6 - AGRADECIMENTOS}

À Universidade Federal de Lavras, à Pró-reitoria de Pós-graduação e ao Departamento de Ciência dos Alimentos (DCA), pela oportunidade de realização do curso de doutorado.

Ao Banco do Nordeste, pela aprovação do projeto e liberação de recursos para a execução do trabalho.

À Escola Agrotécnica Federal de Salinas e ao Centro Federal de Educação Tecnológica de Uberaba, pela liberação parcial para o curso de doutorado.

A todos os que contribuíram direta ou indiretamente na execução do trabalho. 